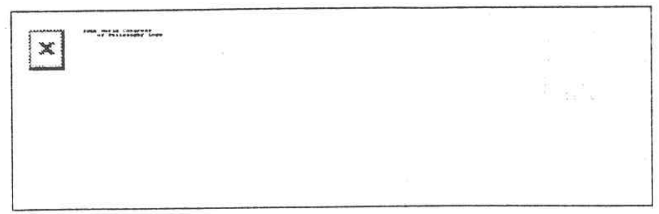

Philosophy of Action

\title{
Happiness through Human Work
}

\author{
C. W. Gichure \\ Kenyatta University \\ focus@africaonline.co.ke
}

\begin{abstract}
In what follows, I analyze the nature of work as human action. From there I discuss the triple dimension of human perfectibility through man's operative powers: the intellect, will and affections or emotions. After that, I focus on human work as the basis for the integration of ethics and practice: the root of human and cultural development of the individual and society.
\end{abstract}

There is abundant bibliography in which man is described as the animal which knows how to resolve problems. He is described as a creature which does not recoil before problems, but resolves them. The invention of the flint, the arrow, the bow, the wheel and the raft, the dagger, etc., are a few good examples of the ingenuity of what we could today call primitive man (L. Polo: 1991). Animals do not find lasting solutions to their problems of survival. When these appear, the species either becomes extinct or the animal ends up by metamorphosing to adjust to the environment. Not so man, who besides having a body and two hands instead of paws or a beak, is endowed with a mind and a will.

But man is not only a resolver of problems for survival. He is also to a great extent their initiator of. Desertification, pollution of the environment, the depletion of the ozone layer, the disasters of Chernobyl, the atomic bomb or any other bomb for that matter, land mines and lead poisoning and so many other problems that mankind faces today have their origin in Science and Technology, i.e., from man's activity. The horrors of Auswitch and the Holocaust, Rwanda and Bosnia are also fruit of man's activity or work. Paraphrasing Cicero one can say that man, through his own activity sets a destiny for himself (De officiis, II, 4,15), for good or for destruction.

The term 'work' is today one of the commonest words on people's lips all over the world. People talk of going to work, coming from work, looking for work or a job. People leave their families, their homes, and even their children, with strangers, so as to go to work. Nor is it uncommon to come ácross people who tell you that they have not the time to think, be with their friends, or their children because of work. Work, therefore has become a culture of a kind. But what kind? 